\title{
REGULAÇÃO DE PROFISSÕES DE SAÚDE NA PERSPECTIVA DO DIREITO COMPARADO: AS DIFERENTES ESTRATÉGIAS REGULATÓRIAS DE ARGENTINA, PARAGUAI, URUGUAI, CANADÁ E AUSTRÁLIA
}

Health workforce regulation from a Comparative Law perspective: The different regulatory strategies of Argentina, Paraguay, Uruguay, Canada and Australia

${ }^{1}$ Universidade de São Paulo. São Paulo/SP, Brasil.

Correspondência: fernando.aith@usp.br

Recebido: 11/02/2019. 
A regulação de profissões de saúde é um tema tão antigo quanto atual.

Por volta do século XVIII a.C. o Rei Hamurabi, da primeira dinastia babilônica, editou o famoso Código de Hamurabi, um conjunto de leis talhadas em uma rocha de diorito e escritas em caracteres cuneiformes que dispõem sobre regras e punições para diversos eventos da vida em sociedade, como comércio, propriedade, família, trabalho, roubo, lei do talião (olho por olho, dente por dente), estupro, pena de morte, práticas médicas e veterinárias, entre outros.

Dentre as regulações previstas há mais de 3.500 anos, voltadas a orientar as práticas médica e veterinária, encontra-se dispositivos como

218. Se um médico trata alguém de uma grave ferida com a lanceta de bronze e o mata ou lhe abre uma incisão com a lanceta de bronze e o olho fica perdido, se lhe deverão cortar as mãos;

219. Se o médico trata o escravo de um liberto de uma ferida grave com a lanceta de bronze e o mata, deverá dar escravo por escravo; 220. Se ele abriu a sua incisão com a lanceta de bronze o olho fica perdido, deverá pagar metade de seu preço;

221. Se um médico restabelece o osso quebrado de alguém ou as partes moles doentes, o doente deverá dar ao médico cinco siclos; $[\ldots]$

224. Se o médico dos bois e dos burros trata um boi ou um burro de uma grave ferida e o animal se restabelece, o proprietário deverá dar ao médico, em pagamento, um sexto de siclo $[. . .]^{1}$.

A tradição de regular práticas profissionais relacionadas ao tratamento médico dos seres humanos manteve-se por toda a história da humanidade. Modernamente, deve-se ressaltar o trabalho de Michel Foucault que examinou o fenômeno que denominou de "medicina de Estado" e destacou com bastante detalhamento a normalização da prática e do saber médicos. Nesse sentido, analisando o que se passou na Alemanha no final do século XVIII e início do século XIX, afirma Foucault:

Com a organização de um saber médico estatal, a normalização da profissão médica, a subordinação dos médicos a uma administração central e, finalmente, a integração de vários médicos em uma organização médica estatal, tem-se uma série de fenômenos inteiramente novos que caracterizam o que pode ser chamada a medicina de Estado².

\footnotetext{
${ }^{1}$ DHNet Direitos Humanos na Internet. Código de Hamurabi. Disponível em: <http://www.dhnet.org.br/ direitos/anthist/hamurabi.htm>. Acesso em: 05 fev. 2019.

${ }^{2}$ FOUCAULT, Michel. O Nascimento da medicina social in Microfísica do Poder. Disponível em: <https://www. nodo50.org/insurgentes/biblioteca/A_Microfisica_do_Poder_-_Michel_Foulcault.pdf>. Acesso em: 05 fev. 2019.
} 
A regulação das profissões voltadas às atividades de diagnóstico e tratamento dos seres humanos consolidou-se, assim, como um campo de regulação estatal sólido e com raízes em todos os Estados Democráticos de Direito modernos.

Com o objetivo de orientar os Estados a respeito da necessidade de uma boa regulação sobre o tema, o sistema de governança global em saúde que emergiu após a Segunda Guerra Mundial vem se ocupando com tal questão de forma cada vez mais detalhada. Nesse sentido, vale destacar a Resolução da Organização Mundial da Saúde WHA 69.19 que define uma "Estratégia Global para Recursos Humanos em Saúde: Força de Trabalho 2030”. Este documento apresenta os principais objetivos, princípios e diretrizes que devem orientar a regulação dos Estados sobre as profissões de saúde, com o objetivo de promover a organização de sistemas de saúde com profissionais aptos a desenvolverem modelos de cobertura universal em saúde.

Considerando que cada sistema de saúde apresenta seus próprios desafios e, ao mesmo tempo, levando-se em conta que a regulação estatal de profissões de saúde exige uma organização jurídico-administrativa para ser implementada de forma eficaz e efetiva, o estudo de direito comparado mostra-se um excelente instrumento de compreensão empírica das diferentes estratégias e experiências colocadas em prática por Estados Democráticos Modernos.

Assim, este número da Revista de Direito Sanitário apresenta, em seu tema em debate, os modelos jurídicos de regulação de profissões de saúde adotados por Argentina, Paraguai, Uruguai, Austrália e Canadá. Os artigos publicados oferecem um quadro extremamente claro e didático sobre como cada um desses países está enfrentando os seus desafios de regulação das profissões de saúde no mundo contemporâneo.

Os pesquisadores Gabrielle Kölling, Isadora da Silveira Steffens e Jameson Vinícius Martins da Silva apresentam o artigo "A regulação da formação graduada de profissionais de saúde na Argentina, Paraguai e Uruguai”. De forma clara e objetiva, mapeiam e analisam a formação graduada em saúde no Mercosul, concentrando-se nos casos de Argentina, Paraguai e Uruguai. Observam os autores, em título de considerações finais, que (i) a excessiva autonomia das universidades e províncias na Argentina são um entrave à harmonização regulatória; que (ii) a centralização das funções na universidade pública e a baixa normatividade no Uruguai também dificultam uma homogeneização de regulação comum; e que a regulação das questões de formação no nível da graduação é muito recente no Paraguai, portanto, ainda há espaço para criação de regulações mais específicas. Em seguida, o professor da Universidade de Toronto, Trudo Lemmens, em conjunto com a doutoranda da mesma universidade, Kanksha Mahadevia Ghimire, apresentam o artigo intitulado "Regulação das profissões de saúde em Ontário: autorregulação com accountability pública baseada em estatutos legais". O trabalho explora o modelo de regulação das profissões de saúde em Ontário, Canadá, um modelo de autorregulação construído 
em torno de um regime estatutário específico. O foco central do artigo é a discussão sobre a Lei de Regulação das Profissões de Saúde de Ontário e os principais componentes de 26 leis que foram promulgadas sob sua égide para regular profissões de saúde específicas.

Para completar esse excelente quadro de estudo de direito comparado sobre o tema de regulação de profissões de saúde, o professor Cameron Stewart Bec, da Universidade de Sydney, publica um instigante artigo denominado "Regulação do profissional de saúde na Austrália: uma visão de antípodas", no qual explora com clareza o modelo australiano, que possui uma singular experiência de criação de uma agência reguladora que reúne diversas profissões de saúde. Ao analisar a regulação dos profissionais de saúde na Austrália, o artigo descreve os poderes constitucionais para regular os serviços de saúde na federação australiana e o sistema criado de direitos de acesso à saúde. A seguir examina a atual Lei Nacional de Regulação do Profissional de Saúde, que tenta criar um sistema regulatório uniforme para os profissionais de saúde na Austrália. O trabalho investiga ainda o funcionamento desse sistema e traz dados atuais sobre sua operação, concluindo com um olhar sobre seus desafios futuros.

Os artigos publicados nesta edição da Revista de Direito Sanitário nos auxiliam a compreender a complexidade do tema e os múltiplos caminhos que podem ser trilhados pelo Estado Democrático para a regulação de profissões de saúde. Uma importante lição que pode ser aprendida com os textos é que, não importa o modelo de regulação, fica evidente que o Estado deve organizar um modelo de regulação de profissões de saúde capaz de, ao mesmo tempo, proteger o interesse público e garantir serviços de saúde resolutivos, de qualidade e humanizados.

\section{Referências}

DHNet Direitos Humanos na Internet. Código de Hamurabi. Disponível em: <http://www. dhnet.org.br/direitos/anthist/hamurabi.htm>. Acesso em: 05 fev. 2019.

FOUCAULT, Michel. O Nascimento da medicina social in Microfísica do Poder. Disponível em: <https://www.nodo50.org/insurgentes/biblioteca/A_Microfisica_do_Poder_-_Michel_ Foulcault.pdf $>$. Acesso em: 05 fev. 2019.

Fernando Mussa Abujamra Aith - Professor Titular da Faculdade de Saúde Pública da Universidade de São Paulo (FSP/USP). Livre-Docente em Teoria Geral do Estado pela Faculdade de Direito da Universidade de São Paulo (FADUSP); pós-doutor em Direito Público pela Faculdade de Direito da Université Paris 2 (França); doutor em Saúde Pública pela FSP/USP; mestre em Filosofia e Teoria Geral do Direito pela FADUSP; graduado em Direito pela FADUSP. Codiretor científico do Núcleo de Pesquisa em Direito Sanitário da USP (NAP-DISA/USP). São Paulo/SP, Brasil. E-mail: fernando.aith@usp.br 